\title{
Systematic Review \\ Oral Microbiota-A New Frontier in the Pathogenesis and Management of Head and Neck Cancers
}

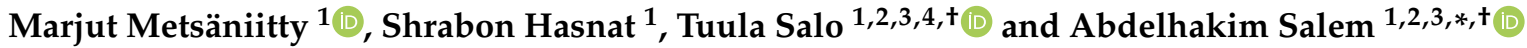 \\ 1 Department of Oral and Maxillofacial Diseases, Clinicum, University of Helsinki, 00014 Helsinki, Finland; \\ marjut.metsaniitty@helsinki.fi (M.M.); shrabon.hasnat@helsinki.fi (S.H.); tuula.salo@helsinki.fi (T.S.) \\ 2 Translational Immunology Research Program (TRIMM), Research Program Unit (RPU), University of \\ Helsinki, 00014 Helsinki, Finland \\ 3 Department of Pathology, Helsinki University Hospital (HUS), 00029 Helsinki, Finland \\ 4 Cancer and Translational Medicine Research Unit, University of Oulu, 90014 Oulu, Finland \\ * Correspondence: abdelhakim.salem@helsinki.fi \\ + These authors jointly supervised this work.
}

Citation: Metsäniitty, M.; Hasnat, S.; Salo, T.; Salem, A. Oral Microbiota-A New Frontier in the Pathogenesis and Management of Head and Neck Cancers. Cancers 2022, 14, 46. https://doi.org/10.3390/ cancers14010046

Academic Editors: Sonika Patial and Sonja M. Kessler

Received: 8 November 2021 Accepted: 21 December 2021 Published: 23 December 2021

Publisher's Note: MDPI stays neutral with regard to jurisdictional claims in published maps and institutional affiliations.

Copyright: (C) 2021 by the authors. Licensee MDPI, Basel, Switzerland. This article is an open access article distributed under the terms and conditions of the Creative Commons Attribution (CC BY) license (https:// creativecommons.org/licenses/by/ $4.0 /)$.
Simple Summary: Head and neck squamous cell carcinoma (HNSCC) is a group of common and aggressive tumors. Recently, oral microbiota has been credited as an important player in carcinogenesis. However, the available knowledge is not always consistent and sometimes conflicting. Therefore, the present comprehensive systematic review of the current clinical reports was conducted to evaluate the role of oral microbiota in HNSCC. Importantly, this study addresses whether oral microbiota targeting could provide diagnostic, prognostic or therapeutic utility in cancer patients. We also discussed the current limitations of this newly emerging field and the potential related strategies for the management of patients with HNSCC and possibly other solid tumors.

\begin{abstract}
Head and neck squamous cell carcinoma (HNSCC) comprises the majority of tumors in head and neck tissues. The prognosis of HNSCC has not significantly improved for decades, signifying the need for new diagnostic and therapeutic targets. Recent evidence suggests that oral microbiota is associated with carcinogenesis. Thus, we conducted a comprehensive systematic review to evaluate the current evidence regarding the role of oral microbiota in HNSCC and whether their targeting may confer diagnostic, prognostic or therapeutic utility. Following the screening of 233 publications retrieved from multiple databases, 34 eligible studies comprising 2469 patients were compiled and critically appraised. Importantly, many oral pathogens, such as Porphyromonas gingivalis and Fusobacterium nucleatum were linked to certain oral potentially malignant lesions and various types of HNSCC. Furthermore, we summarized the association between the expression profiles of different oral bacterial species and their tumorigenic and prognostic effects in cancer patients. We also discussed the current limitations of this newly emerging area and the potential microbiota-related strategies for preventing and treating HNSCC. Whilst many clinical studies are underway to unravel the role of oral microbiota in cancer, the limited available data and experimental approaches reflect the newness of this promising yet challenging field.
\end{abstract}

Keywords: microbiome; DNA/RNA sequencing; cancer; head and neck squamous cell carcinoma; metastasis; biomarker; prognosis; treatment

\section{Introduction}

Head and neck squamous cell carcinoma (HNSCC) arises from the mucosal lining of the oral cavity, pharynx and larynx and it comprises the majority of tumors in the head and neck region [1,2]. Globally, HNSCCs are among the most prevalent cancers with an estimated incidence of 880,000 new cases and 440,000 deaths in 2020 alone [3]. In India, oral squamous cell carcinoma (OSCC) is causing most of the cancer-related deaths among men [3]. The 5-year survival rate of HNSCC remains low and has not significantly 
improved over the past years especially for metastatic lesions [4]. Tobacco consumption, alcohol abuse and infection with human papillomavirus (HPV) in adult males are the key risk factors for developing HNSCC. However, an increasing incidence of aggressive OSCC has been reported in young female patients with no history of exposure to such traditional risk factors [5]. Thus, there is an urgent need to identify new risk factors that could provide prognostic and therapeutic targets in HNSCC.

The oral microbiome consists of up to 750 microorganisms including bacteria, archaea, protozoa, fungi, and viruses [6,7]. In the oral cavity, microbial colonies can grow on hard and soft tissues including tongue, buccal mucosa, tonsils and palate. These surfaces provide different growth conditions and therefore the biofilms can significantly differ in their composition [6]. In a healthy state there is an equilibrium between these species, where the diversity and relative proportions are stable. In dysbiosis, however, such equilibrium is disrupted and followed by a compositional shift towards proinflammatory commensals with a reduction of beneficial microbes. These microbial changes could result in long lasting inflammatory conditions such as periodontitis [8].

An amassing body of evidence supports the association between oral microbiota and cancer. Oral dysbiosis can influence tumorigenesis by suppressing the immune response, synthesizing potent mutagens (e.g., acetaldehyde), and mediating chronic proinflammatory conditions [8,9]. Periodontitis, in this regard, has been linked to an increased incidence and poor survival of cancer $[9,10]$. In addition, certain oral potentially malignant disorders (OPMDs) were associated with dysbiosis $[9,11]$. However, data reporting the role of oral microbiota in cancer is not always consistent. On the one hand, bacterial genotoxins, such as cytolethal distending toxins, can promote DNA damage in the host cells. Furthermore, increased levels of bacterial species including Fusobacterium nucleatum (F. nucleatum) and Porphyromonas gingivalis ( $P$. gingivalis) were associated with colorectal and pancreatic cancers, respectively $[9,11]$. On the other hand, oral microbiota were shown to mediate anti-tumor effects through carcinogen inactivation [9,12]. Additionally, bacterial-derived outer membrane vesicles have immunomodulatory effects and hence were suggested as novel therapeutic agents in cancer $[13,14]$. Therefore, we aimed to compile and analyze the current evidence regarding the association between oral microbiota and the various aspects of carcinogenesis and their potential clinical utility in patients with HNSCC.

\section{Materials and Methods}

\subsection{Protocol and Study Registration}

The protocol of this study was designed according to the recommendations of the Preferred Reporting Items for Systematic Reviews and Meta-Analysis (PRISMA). The study was retroactively registered in the International Prospective Register of Systematic Reviews (PROSPERO; registration number CRD42021256877) prior to the initiation of the systematic search [15].

\subsection{Inclusion and Exclusion Criteria}

We included original research studies that assessed the relationship between oral microbiota and the tumorigenesis of HNSCC in human samples. The detailed inclusion and exclusion criteria are listed in the Table S1.

\subsection{Search Strategy and Study Screening}

The literature search was conducted on the 13th of June 2021 without restrictions through four electronic databases: PubMed, Web of Science, Ovid Medline, and Cochrane. The applied search terms included: (("oral microbiota") OR ("oral microbiome") OR ("oral bacteria *") OR ("oral microbial") OR ("oral microorganism") OR ("oral microbe")) AND (("head and neck squamous cell carcinoma") OR ("head and neck neoplasms") OR ("head and neck cancer") OR ("head and neck squamous cell cancer") OR ("oral cancer") OR ("mouth neoplasms") OR ("laryngeal neoplasms") OR ("gingival neoplasms") OR ("lip neoplasms") OR ("palatal neoplasms") OR ("tongue neoplasms") OR ("pharyngeal neoplasms")). Following deduplication, studies were first assessed for eligibility, and then 
further screened for qualitative assessment. Two reviewers (MM and SH) independently screened and assessed the literatures. Differences in the results, if any, were resolved through discussion with a third reviewer (AS).

\subsection{Data Extraction and Study Items}

Extracted data were tabulated using the online collaborative tool Google Sheets ${ }^{\mathrm{TM}}$ (Google, Menlo Park, CA, US). The following key items were extracted from the eligible studies: The 1st author's name, publication year, title, country, total number and age of patients, sample type, oral microbiota, tumor (type, location, stage, grade), Epstein Barr virus (EBV)/HPV status, methods, antibodies (name, dilution, company, etc.), p-value, confidence interval $(\mathrm{CI})$, hazard ratio (HR), and prognostic data whenever applicable. Data extraction was performed and verified independently by two reviewers (MM and SH).

\subsection{Assessment of Reporting Quality and the Risk of Bias}

The included prognostic studies were evaluated using items adapted from the Reporting Recommendations for Tumor Marker Prognostic Studies (REMARK) guidelines [16]. The assessment criteria are detailed in the Table S2. For analyzing the risk of bias, we used the Meta-Analysis of Statistics Assessment and Review Instrument (MAStARI) tool as we recently described [17]. The assessment was performed independently by two reviewers (MM and $\mathrm{SH}$ ). Disparities, if any, were resolved through discussion with a third reviewer (AS).

\section{Results}

\subsection{Study Selection}

A total of 536 studies were retrieved through the initial searches. After deduplication, 233 articles were identified and screened for eligibility. Of these, 34 studies were deemed relevant and selected for further qualitative analysis and data extraction. The search and selection process is summarized in Figure 1.

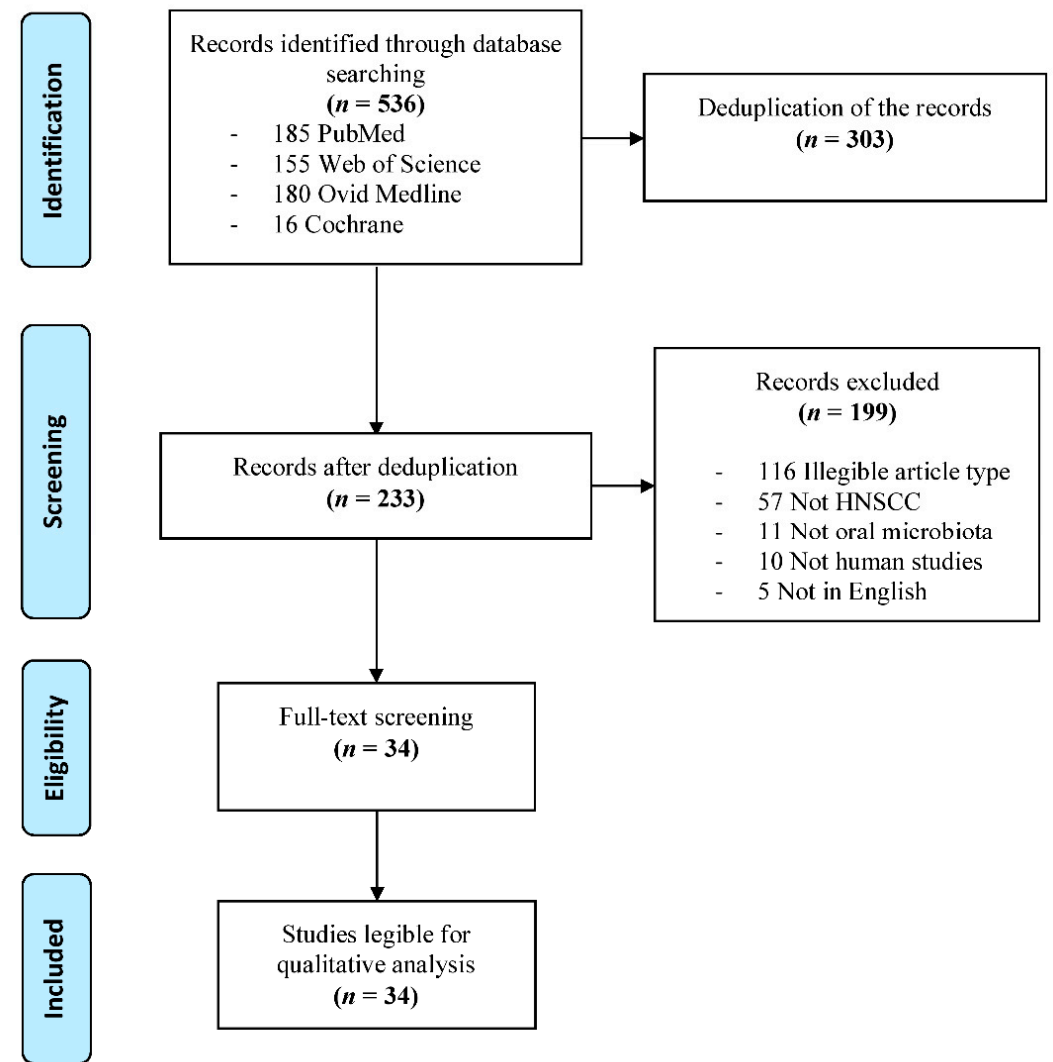

Figure 1. PRISMA flowchart of the study selection process. 


\subsection{Baseline Characteristics of the Studies}

The included 34 studies comprised a total of 4432 participants (including 2294 cancer patients, 175 OPMDs and 1963 cancer-free controls). Studies were conducted between 2005-2021 and they were based in the following countries: US $(n=10)$, Taiwan $(n=5)$, China $(n=5)$, India $(n=3)$, Japan $(n=2)$, Malaysia $(n=1)$, Australia $(n=1)$, Sri Lanka $(n=1)$, New Zealand $(n=1)$, Colombia $(n=1)$, Hong Kong $(n=1)$, Poland $(n=1)$, Brazil $(n=1)$, and France $(n=1)$. The samples were obtained from patients with HNSCC, of which OSCC was the most frequently studied tumor [18-42]. The studies also included samples from the following: oropharyngeal squamous cell carcinoma (OPSCC) [21,43] gingival squamous cell carcinoma (GSCC) [44]; unspecified oral cavity cancer (OCC) (45); oropharyngeal cancers (OPC) [45]; nasopharyngeal carcinoma (NPC) [46]; unspecified HNSCCs [47-51]. In addition, certain oral potentially malignant disorders (OPMDs), such as oral leukoplakia, were also studied. The main characteristics of the included studies are listed in Table 1.

The16S ribosomal RNA (rRNA) gene polymerase chain reaction (PCR) was the most commonly used approach for oral bacterial detection and identification. The sampling and characterization methods of the oral microbiota are summarized in Table 2 and Figure 2.

Table 1. The baseline characteristics of the included studies.

\begin{tabular}{|c|c|c|c|c|c|c|c|c|}
\hline Study & $\begin{array}{l}\text { Study } \\
\text { Origin }\end{array}$ & $\begin{array}{l}\text { Lesion } \\
\text { Type(s) }\end{array}$ & Lesion Site(s) & $\begin{array}{c}\text { Tumor } \\
\text { Stage/Grade }\end{array}$ & $\begin{array}{l}\text { Number of } \\
\text { Lesion Cases }\end{array}$ & Age (Years) & $\begin{array}{l}\text { Gender } \\
\mathbf{M} / \mathbf{F}\end{array}$ & Study Period \\
\hline [18] & US & OSCC & Oral cavity & - & 45 & $57.6( \pm 2.34)(\mathrm{M})$ & $32 / 13$ & - \\
\hline [44] & US & GSCC & Gingiva & - & 10 & - & - & - \\
\hline [19] & US & OSCC & Floor of the mouth & - & 3 & $>50$ & $3 / 0$ & - \\
\hline [20] & US & OsCC & $\begin{array}{l}\text { Tongue, floor of the } \\
\text { mouth }\end{array}$ & $\mathrm{T} 1-\mathrm{T} 4 \mathrm{~b}, \mathrm{~N} 0-\mathrm{N} 2 \mathrm{~b}$ & 10 & 59 (Med) & t. & - \\
\hline [41] & US & $\begin{array}{l}\text { OSCC, } \\
\text { OPMDs }\end{array}$ & $\begin{array}{l}\text { Buccal mucosa, tongue, } \\
\text { gingiva, alveolar ridge, } \\
\text { floor of the mouth, } \\
\text { retromolar trigone }\end{array}$ & $\begin{array}{c}\text { Study 1: pT2-pT4, } \\
\text { N0-N2b; Study 2: } \\
\text { CIS, T1-T4b, } \\
\text { N0-N2b }\end{array}$ & $\begin{array}{l}\text { Study 1: 5; } \\
\text { Study 2: 16; } \\
\text { OPMDs: } 8\end{array}$ & $\begin{array}{l}\text { Study 1: 69.2; Study 2: } \\
\text { 63.37; OPMDs: } 58.5(\mathrm{M})\end{array}$ & $18 / 11$ & 2011-2012 \\
\hline [21] & US & $\begin{array}{l}\text { OSCC, } \\
\text { OPSCC }\end{array}$ & Oral cavity, oropharynx & - & 121 & 58 (Med) & $94 / 27$ & 2011-2013 \\
\hline [22] & Taiwan & $\begin{array}{l}\text { OSCC, } \\
\text { OPMDs }\end{array}$ & $\begin{array}{l}\text { Tongue, floor of the } \\
\text { mouth, lip, buccal } \\
\text { mucosa, alveolar ridge, } \\
\text { hard palate }\end{array}$ & I-IV & $\begin{array}{l}\text { OSCC: } 125 ; \\
\text { OPMDs: } 124\end{array}$ & $\begin{array}{c}\text { OSCC: } 53 \pm 10 \\
\text { OPMDs: } 50 \pm 11(\mathrm{M})\end{array}$ & $223 / 26$ & 2014-2015 \\
\hline [42] & Malaysia & $\begin{array}{l}\text { OSCC, } \\
\text { OPMDs }\end{array}$ & Oral cavity & - & 18 (9 per group) & $\begin{array}{l}\text { OSCC: 60; OPMDs: } \\
54(\mathrm{M})\end{array}$ & $6 / 12$ & - \\
\hline [47] & US & HNSCC & $\begin{array}{l}\text { Oral cavity, oropharynx, } \\
\text { hypopharynx, larynx }\end{array}$ & I-IV & 121 & $63 \pm 11(\mathrm{M})$ & $74 / 47$ & 2003-2014 \\
\hline [23] & China & OSCC & Oral cavity & - & 40 & 62 (Med) & $24 / 16$ & - \\
\hline [48] & US & HNSCC & $\begin{array}{l}\text { Oral cavity, pharynx, } \\
\text { larynx }\end{array}$ & - & 129 & $\begin{array}{l}\text { Group 1: 71; 2: } \\
\quad 62.7(\mathrm{M})\end{array}$ & $100 / 29$ & 1992-2010 \\
\hline [24] & Taiwan & OSCC & Oral cavity & - & 138 & $\begin{array}{c}54.7 \pm 1.2 \\
53.4 \pm 1.3(\mathrm{M})\end{array}$ & - & 2010-2013 \\
\hline [45] & Australia & OCC, OPC & Oral cavity, oropharynx & I-IV & 52 & $65(\mathrm{M})$ & $46 / 6$ & - \\
\hline [25] & Sri Lanka & OSCC & Tongue, buccal mucosa & Well/moderately diff. & 25 & $61.00 \pm 9.5(\mathrm{M})$ & $25 / 0$ & - \\
\hline [50] & $\begin{array}{c}\text { New } \\
\text { Zealand }\end{array}$ & HNSCC & $\begin{array}{l}\text { Oral cavity, } \\
\text { left parotid, tonsils }\end{array}$ & - & 14 & 49-81 (Range) & $11 / 3$ & - \\
\hline [26] & Taiwan & OSCC & $\begin{array}{l}\text { Tongue, gingiva, floor } \\
\text { of the mouth }\end{array}$ & I-IV & 197 & 32-87 (Range) & $177 / 20$ & - \\
\hline [27] & Taiwan & OSCC & $\begin{array}{l}\text { Buccal mucosa, tongue, } \\
\text { lip, gingiva, others }\end{array}$ & I-IV & 39 & $53.33 \pm 10.95(\mathrm{M})$ & $39 / 0$ & 2014-2015 \\
\hline [28] & US & OSCC & 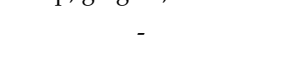 & $\begin{array}{l}\text { Non-metastatic } \\
\text { OSCC }\end{array}$ & 4 & 40-64 (Range) & $4 / 0$ & - \\
\hline [29] & US & $\begin{array}{l}\text { OSCC, } \\
\text { OPMDs }\end{array}$ & Oral cavity & 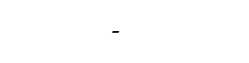 & $\begin{array}{l}\text { OSCC: } 18 ; \\
\text { OPMDs: } 8\end{array}$ & $\begin{array}{c}\text { OSCC: } 59.8 \pm 10.9 \\
\text { OPMDs: } 66.1 \pm 17.9(\mathrm{M})\end{array}$ & $16 / 10$ & - \\
\hline$[30]$ & Japan & $\begin{array}{l}\text { OSCC, } \\
\text { OPMDs }\end{array}$ & $\begin{array}{l}\text { Tongue, gingiva, } \\
\text { buccal mucosa }\end{array}$ & CIS, I-IV & 12 (6 per group) & $\begin{array}{c}\text { OSCC: } 50.66 \text {; OPMDs: } \\
58.33(\mathrm{M})\end{array}$ & $9 / 3$ & - \\
\hline [43] & Colombia & OPSCC & Oropharynx & - & 26 & $31 \geq 70$ (Range) & $17 / 9$ & 2014-2017 \\
\hline [31] & Japan & OSCC & Oral cavity & T1-4, N0-3 & 60 & $63.7(\mathrm{M})$ & $50 / 10$ & 2016-2018 \\
\hline [32] & China & OSCC & Buccal mucosa & I-IV & 50 & $60.7(\mathrm{M}) ; 61$ (Med) & $32 / 18$ & 2018 \\
\hline [49] & $\begin{array}{l}\text { Hong } \\
\text { Kong }\end{array}$ & HNSCC & $\begin{array}{l}\text { Oral cavity, oropharynx, } \\
\text { larynx and others }\end{array}$ & T1-4, N0-2 & 68 & $>60 y=48, \leq 60 y=20$ & $51 / 17$ & 2015-2018 \\
\hline [46] & China & NPC & Nasopharynx & - & 499 & $48.4(\mathrm{M})$ & $356 / 143$ & 2010-2014 \\
\hline [33] & India & $\begin{array}{l}\text { OSCC, } \\
\text { OPMDs }\end{array}$ & $\begin{array}{l}\text { Floor of the mouth, } \\
\text { buccal mucosa, } \\
\text { tongue, gingiva }\end{array}$ & $\begin{array}{l}\text { Well/moderately/ } \\
\text { poorly diff.; Lymph } \\
\text { node status }(+/-)\end{array}$ & $\begin{array}{l}\text { OSCC: } 31 \\
\text { OPMDs: } 20\end{array}$ & $\begin{array}{l}\text { OSCC: } 49.31 \pm 13.24 \\
\text { OPMDs: } 45.67 \pm 6.81(\mathrm{M})\end{array}$ & - & - \\
\hline [34] & Poland & OSCC & $\begin{array}{l}\text { Tonsil, throat, floor of } \\
\text { the mouth, tongue }\end{array}$ & - & 18 & - & - & - \\
\hline [35] & China & OSCC & Oral cavity & I-IV & 24 & $61.1 \pm 12.4(\mathrm{M})$ & $17 / 7$ & - \\
\hline
\end{tabular}


Table 1. Cont.

\begin{tabular}{|c|c|c|c|c|c|c|c|c|}
\hline Study & $\begin{array}{l}\text { Study } \\
\text { Origin }\end{array}$ & $\begin{array}{l}\text { Lesion } \\
\text { Type(s) }\end{array}$ & Lesion Site(s) & $\begin{array}{c}\text { Tumor } \\
\text { Stage/Grade }\end{array}$ & $\begin{array}{l}\text { Number of } \\
\text { Lesion Cases }\end{array}$ & Age (Years) & $\begin{array}{c}\text { Gender } \\
\mathbf{M} / \mathbf{F}\end{array}$ & Study Period \\
\hline [51] & China & HNSCC & $\begin{array}{l}\text { Larynx, hypopharynx, } \\
\text { other }\end{array}$ & I-IV & 56 & $61.5 \pm 8.8(\mathrm{M})$ & $56 / 0$ & - \\
\hline$[36]$ & Brazil & OsCC & $\begin{array}{l}\text { Oral cavity (non-active } \\
\text { lesion: L0; active L1) }\end{array}$ & $\begin{array}{l}\text { T1-4; Lymph node } \\
\text { status }(+/-)\end{array}$ & 16 (8 per group) & L0: 55.8; L1: 57.7 (M) & $14 / 2$ & - \\
\hline [37] & France & OSCC & Oral cavity & I-IV & 151 & 57 (Med) & $93 / 58$ & 1990-2006 \\
\hline [38] & India & OscC & - & $\begin{array}{c}\text { T2-4, N0-3; } \\
\text { Well/mod diff. }\end{array}$ & 25 & $55.32(\mathrm{M})$ & $16 / 9$ & - \\
\hline [39] & India & OsCC & - & Well diff. & 50 & $52.68(\mathrm{M})$ & $32 / 18$ & - \\
\hline$[40]$ & Taiwan & OSCC & Buccal mucosa & I-IV & 116 & $54.81 \pm 10.73$ & $116 / 0$ & - \\
\hline
\end{tabular}

† The authors stated that the samples $(n=10)$ consisted of $53 \%$ male and $47 \%$ female. CIS, carcinoma in situ; Diff., differentiated; $\mathrm{M}$, mean; Med, median; $\mathrm{M} / \mathrm{F}$, male/female; $N$, lymph node status; $\mathrm{T}$, tumor size; $\mathrm{pT}$, pathological tumor size; HNSCC, head and neck squamous cell carcinoma; NPC, nasopharyngeal cancer; OCC, oral cavity cancer; OPC, oropharyngeal cancer; OPMDs, oral potentially malignant disorders; OSCC, oral squamous cell carcinoma.

Table 2. The various methods applied in the included studies.

\begin{tabular}{|c|c|c|c|c|c|}
\hline Study & Method & Sampling Type & Number of Samples & Microbiota Type & Microbiota Characterization \\
\hline [18] & $\begin{array}{l}\text { DNA-DNA } \\
\text { hybridization }\end{array}$ & $\begin{array}{l}\text { Whole unstimulated } \\
\text { saliva through } \\
\text { expectoration }\end{array}$ & $\begin{array}{l}274 \text { (229 OSCC-free } \\
\text { controls; } 45 \text { OSCC) }\end{array}$ & $\begin{array}{l}40 \text { common } \\
\text { oral bacteria } \\
\text { were tested }\end{array}$ & $\begin{array}{l}\text { Digoxigenin-labeled DNA } \\
\text { using random primer } \\
\text { technique was used }\end{array}$ \\
\hline [44] & $\mathrm{IHC}$ & Tissue biopsy, PEFF & $\begin{array}{c}15 \text { (5 normal tissue; } \\
10 \text { GSCC) }\end{array}$ & $\begin{array}{l}\text { P. gingivalis; } \\
\text { S. gordonii }\end{array}$ & $\begin{array}{l}\text { Rabbit polyclonal } \\
\text { antibodies }(1: 1000)\end{array}$ \\
\hline [19] & 16S rRNA PCR & Stimulated saliva & $\begin{array}{l}5 \text { (2 matched non-OSCC } \\
\text { controls; } 3 \text { OSCC) }\end{array}$ & $\begin{array}{l}\text { Total bacterial } \\
\text { diversity and } \\
\text { relative abundance }\end{array}$ & $\begin{array}{l}\text { PCR primers were based on the } \\
\text { V4-V5 hypervariable region }\end{array}$ \\
\hline [20] & 16S rRNA PCR & $\begin{array}{l}\text { DNA extraction from } \\
\text { tissue biopsy samples }\end{array}$ & $\begin{array}{l}20 \text { (10 tumor-free tissues } \\
\text { from OSCC patients; } \\
10 \text { OSCC) }\end{array}$ & $\begin{array}{l}\text { Total bacterial } \\
\text { diversity and } \\
\text { relative abundance }\end{array}$ & $\begin{array}{c}\text { PCR primers for V4-V5 } \\
\text { hypervariable region; the } \\
\text { eubacterial primers: prbac1 } \\
\text { and prbac2 }\end{array}$ \\
\hline [41] & 16S rRNA PCR & $\begin{array}{l}\text { Swab samples from } \\
\text { normal controls } \\
\text { and lesions }\end{array}$ & $\begin{array}{l}83 \text { (49 normal controls; } \\
34 \text { OSCC/OPMDs) }\end{array}$ & $\begin{array}{l}\text { Total bacterial } \\
\text { diversity and } \\
\text { relative abundance }\end{array}$ & $\begin{array}{l}16 \mathrm{~S} \text { rDNA V4 hypervariable } \\
\text { region were sequenced using the } \\
\text { Illumina MiSeq platform }\end{array}$ \\
\hline [21] & 16S rRNA PCR & Oral rinse samples & $\begin{array}{l}363 \text { (242 normal controls; } \\
121 \text { OSCC/OPSCC cases) }\end{array}$ & $\begin{array}{l}\text { Total bacterial } \\
\text { diversity and } \\
\text { relative abundance }\end{array}$ & $\begin{array}{l}\text { The Illumina MiSeq primers } \\
\text { targeting the V4 variable region }\end{array}$ \\
\hline [22] & 16S rRNA PCR & Unstimulated saliva & $\begin{array}{l}376 \text { (127 normal controls; } \\
124 \text { OPMDs; } 125 \text { OSCC) }\end{array}$ & $\begin{array}{l}\text { Total bacterial } \\
\text { diversity and } \\
\text { relative abundance }\end{array}$ & $\begin{array}{c}\text { The PCR primer pair (F515/ R806) } \\
\text { targeting the V4 region of } \\
\text { bacterial } 16 \mathrm{~S} \text { rDNA }\end{array}$ \\
\hline [42] & 16S rRNA PCR & $\begin{array}{l}\text { Swab samples from } \\
\text { normal controls } \\
\text { and lesions }\end{array}$ & $\begin{array}{l}27 \text { (9 normal controls; } \\
9 \text { OPMDs; } 9 \text { cancer) }\end{array}$ & $\begin{array}{l}\text { Total bacterial } \\
\text { diversity and } \\
\text { relative abundance }\end{array}$ & $\begin{array}{l}\text { The primer pair D88/E94 } \\
\text { produced near full length of } 16 \mathrm{~S} \\
\text { amplicons (targets V6-V9) }\end{array}$ \\
\hline [47] & 16S rRNA PCR & $\begin{array}{l}\text { Paired normal and } \\
\text { tumoral resection } \\
\text { specimens }\end{array}$ & $\begin{array}{l}242 \text { (121 tumor-free } \\
\text { controls; } 121 \text { tumors) }\end{array}$ & $\begin{array}{l}\text { Total bacterial } \\
\text { diversity and } \\
\text { relative abundance }\end{array}$ & $\begin{array}{l}\text { PCR of the V1-V4 hypervariable } \\
\text { regions of the } 16 S \text { rRNA gene } \\
\text { using the M13 primers }\end{array}$ \\
\hline [23] & 16S rRNA PCR & $\begin{array}{l}\text { Swab samples from } \\
\text { normal controls } \\
\text { and lesions }\end{array}$ & $\begin{array}{l}80 \text { (40 anatomically } \\
\text { matched normal controls; } \\
\qquad 40 \text { OSCC) }\end{array}$ & $\begin{array}{l}\text { Total bacterial } \\
\text { diversity and } \\
\text { relative abundance }\end{array}$ & $\begin{array}{l}\text { The PCR primer pair }(515 \mathrm{~F} / 926 \mathrm{R}) \\
\text { targeting the V4-V5 regions using } \\
\text { Illumina MiSeq tool }\end{array}$ \\
\hline [48] & 16S rRNA PCR & Mouth wash samples & $\begin{array}{l}383 \text { ( } 254 \text { matched normal } \\
\text { controls; } 129 \text { HNSCC) }\end{array}$ & $\begin{array}{l}\text { Total bacterial } \\
\text { diversity and } \\
\text { relative abundance }\end{array}$ & $\begin{array}{l}\text { The PCR primer pair }(347 \mathrm{~F} / 803 \mathrm{R}) \\
\text { targeting the V3-V4 variable } \\
\text { regions of the } 16 \mathrm{~S} \text { rRNA }\end{array}$ \\
\hline [24] & 16S rRNA PCR & $\begin{array}{l}\text { Unstimulated saliva; } \\
\text { peripheral blood } \\
\text { (genotyping) }\end{array}$ & $\begin{array}{c}289 \text { (151 matched controls; } \\
138 \text { OSCC })\end{array}$ & $\begin{array}{l}20 \text { species were } \\
\text { included for } \\
\text { case-control } \\
\text { comparison }\end{array}$ & $\begin{array}{c}\text { The PCR primer pair (341F/926R) } \\
\text { targeting the V3-V5 regions } \\
\text { of the } 16 \mathrm{~S} \text { rRNA }\end{array}$ \\
\hline [45] & 16S rRNA PCR & Oral rinse samples & $\begin{array}{l}83 \text { (20 normal controls; } \\
11 \text { high-risk; } 52 \text { tumors) }\end{array}$ & $\begin{array}{l}\text { Total bacterial } \\
\text { diversity and } \\
\text { relative abundance }\end{array}$ & $\begin{array}{c}\text { The PCR primer pair }(515 \mathrm{~F} / 806 \mathrm{R}) \\
\text { targeting the } \mathrm{V} 4 \text { variable region of } \\
\text { the } 16 \mathrm{~S} \text { rRNA }\end{array}$ \\
\hline [25] & 16S rRNA PCR & Tissue biopsy samples & $\begin{array}{c}52 \text { ( } 27 \text { oral fibroepithelial } \\
\text { polyp as controls; } 25 \text { OSCC) }\end{array}$ & $\begin{array}{l}\text { Total bacterial } \\
\text { diversity and } \\
\text { relative abundance }\end{array}$ & $\begin{array}{l}\text { The PCR primer pair } \\
\text { (27FYMF/519R) targeting the } \\
\text { V1-V3 regions of the } 16 \mathrm{~S} \text { rRNA }\end{array}$ \\
\hline [50] & 16S rRNA PCR & $\begin{array}{l}\text { Unstimulated } \\
\text { whole saliva }\end{array}$ & $\begin{array}{c}30 \text { (7 healthy controls; } \\
9 \text { dental compromised; } \\
14 \text { HNSCC) }\end{array}$ & $\begin{array}{l}\text { Total bacterial } \\
\text { diversity and } \\
\text { relative abundance }\end{array}$ & $\begin{array}{l}\text { The PCR primer pair }(341 \mathrm{~F} / 806 \mathrm{R}) \\
\text { targeting the } \mathrm{V} 3-\mathrm{V} 4 \text { variable } \\
\text { regions of the } 16 \mathrm{~S} \text { rRNA }\end{array}$ \\
\hline
\end{tabular}


Table 2. Cont.

\begin{tabular}{|c|c|c|c|c|c|}
\hline Study & Method & Sampling Type & Number of Samples & Microbiota Type & Microbiota Characterization \\
\hline [26] & 16S rRNA PCR & Oral rinse samples & $\begin{array}{c}248 \text { (51 healthy individuals; } \\
197 \text { OSCC) }\end{array}$ & $\begin{array}{l}\text { Total bacterial } \\
\text { diversity and } \\
\text { relative abundance }\end{array}$ & $\begin{array}{l}\text { The PCR primer pair (16SF/16SR) } \\
\text { targeting the V3-V4 variable } \\
\text { regions of the } 16 \mathrm{~S} \text { rRNA }\end{array}$ \\
\hline [27] & 16S rRNA PCR & $\begin{array}{l}\text { Unstimulated } \\
\text { saliva samples }\end{array}$ & 39 (OSCC) & $\begin{array}{l}\text { Total bacterial } \\
\text { diversity and } \\
\text { relative abundance }\end{array}$ & $\begin{array}{c}\text { The PCR primers (F515/R806) } \\
\text { targeting the V4 region } \\
\text { of the } 16 \mathrm{~S} \text { rRNA }\end{array}$ \\
\hline [28] & RNA amplification & Oral swab samples & $\begin{array}{l}15 \text { (4 OSCC; } 11 \text { OSCC-free } \\
\text { sites/healthy individuals) }\end{array}$ & $\begin{array}{l}\text { Active communities } \\
\text { in tumor / tumor- } \\
\text { free areas }\end{array}$ & $\begin{array}{l}\text { Illumina adapter-specific primers } \\
\text { were used to amplify the cDNA } \\
\text { generated from mRNA }\end{array}$ \\
\hline [29] & 16S rRNA PCR & Oral rinse samples & $\begin{array}{c}38 \text { (12 thyroid nodules as } \\
\text { controls; } 18 \text { OSCC; } \\
8 \text { OPMDs) }\end{array}$ & $\begin{array}{l}\text { Total bacterial } \\
\text { diversity and } \\
\text { relative abundance }\end{array}$ & $\begin{array}{l}\text { The PCR primer pair (347F / 803R) } \\
\text { targeting the V3-V4 variable } \\
\text { regions of the } 16 \mathrm{~S} \text { rRNA }\end{array}$ \\
\hline [30] & 16S rRNA PCR & $\begin{array}{l}\text { Unstimulated } \\
\text { saliva samples }\end{array}$ & $\begin{array}{l}16 \text { (4 healthy controls; } \\
6 \text { OSCC; } 6 \text { OPMDs) }\end{array}$ & $\begin{array}{l}\text { Total bacterial } \\
\text { diversity and } \\
\text { relative abundance }\end{array}$ & $\begin{array}{l}\text { The PCR primers (F515/R806) } \\
\text { targeting the V4 gene region of } \\
\text { the } 16 \mathrm{~S} \text { rRNA }\end{array}$ \\
\hline [43] & 16S rRNA PCR & $\begin{array}{c}\text { Cytobrush (control); } \\
\text { Tissue biopsy (OPSCC) }\end{array}$ & 52 (26 OPSCC; 26 controls) & $\begin{array}{l}\text { P. melanogenica, } \\
\text { F. naviforme, } \\
\text { S. anginosus }\end{array}$ & $\begin{array}{c}\text { Species-specific construct was } \\
\text { designed that contained analyzed } \\
\text { bacteria sequences }\end{array}$ \\
\hline [31] & 16S rRNA PCR & $\begin{array}{c}\text { Stimulated } \\
\text { saliva samples }\end{array}$ & $\begin{array}{c}140 \text { (80 non-cancer controls; } \\
60 \text { OSCC) }\end{array}$ & $\begin{array}{l}\text { Total bacterial } \\
\text { diversity and } \\
\text { relative abundance }\end{array}$ & $\begin{array}{l}\text { PCR primers were developed } \\
\text { for V3-V4 region of the } \\
\text { 16S rRNA gene }\end{array}$ \\
\hline [32] & 16S rRNA PCR & $\begin{array}{l}\text { Oral swabs from tumor } \\
\text { and normal tissues }\end{array}$ & $\begin{array}{l}100 \text { (50 from non-tumor } \\
\text { sites; } 50 \text { tumors) }\end{array}$ & $\begin{array}{l}\text { Total bacterial } \\
\text { diversity and } \\
\text { relative abundance }\end{array}$ & $\begin{array}{l}\text { The PCR primer pair }(338 \mathrm{~F} / 806 \mathrm{R}) \\
\text { targeting the } \mathrm{V} 3-\mathrm{V} 4 \text { variable } \\
\text { regions of the } 16 \mathrm{~S} \text { rRNA }\end{array}$ \\
\hline [49] & 16S rRNA PCR & $\begin{array}{l}\text { Oral rinse samples; } \\
\text { Tissue biopsy }\end{array}$ & $\begin{array}{l}272 \text { (136 non-tumor } \\
\text { controls; } \\
136 \text { tumor samples) }\end{array}$ & $\begin{array}{l}\text { Total bacterial } \\
\text { diversity and } \\
\text { relative abundance }\end{array}$ & $\begin{array}{l}\text { The PCR primer pair }(341 \mathrm{~F} / 806 \mathrm{R}) \\
\text { targeting the } \mathrm{V} 3-\mathrm{V} 4 \text { variable } \\
\text { regions of the } 16 \mathrm{~S} \text { rRNA }\end{array}$ \\
\hline$[46]$ & 16S rRNA PCR & Saliva samples & $\begin{array}{l}994 \text { (495 healthy controls; } \\
499 \text { patients with NPC) }\end{array}$ & $\begin{array}{c}\text { Total bacterial } \\
\text { diversity and ASVs } \\
\text { prevalence }\end{array}$ & $\begin{array}{l}\text { The PCR primer pair }(341 \mathrm{~F} / 805 \mathrm{R}) \\
\text { targeting the } \mathrm{V} 3-\mathrm{V} 4 \text { variable } \\
\text { regions of the } 16 \mathrm{~S} \text { rRNA }\end{array}$ \\
\hline [33] & 16S rRNA PCR & $\begin{array}{l}\text { Unstimulated whole } \\
\text { mouth fluid }\end{array}$ & $\begin{array}{l}74 \text { (23 healthy controls; } \\
31 \text { OSCC; } 20 \text { OPMDs) }\end{array}$ & $\begin{array}{l}\text { Total bacterial } \\
\text { diversity and } \\
\text { relative abundance }\end{array}$ & $\begin{array}{l}\text { The PCR primer pair }(319 \mathrm{~F} / 806 \mathrm{R}) \\
\text { targeting the } \mathrm{V} 3-\mathrm{V} 4 \text { variable } \\
\text { regions of the } 16 \mathrm{~S} \text { rRNA }\end{array}$ \\
\hline [34] & 16S rRNA PCR & $\begin{array}{l}\text { Saliva samples; } \\
\text { Tissue biopsy }\end{array}$ & $\begin{array}{l}59 \text { (18 non-tumor tissues; } \\
18 \text { tumor tissue; } \\
23 \text { OSCC saliva) }\end{array}$ & $\begin{array}{l}\text { Total bacterial } \\
\text { diversity and } \\
\text { relative abundance }\end{array}$ & $\begin{array}{l}\text { Adaptor-ligated } 16 \mathrm{~S} \text { primers } \\
\text { targeting the V4 region of the } 16 \mathrm{~S} \\
\text { rRNA gene fragment }\end{array}$ \\
\hline [35] & $16 S$ rRNA PCR & Tissue biopsy samples & $\begin{array}{c}48 \text { (24 paracancerous } \\
\text { control tissues; } \\
24 \text { tumor tissues) }\end{array}$ & $\begin{array}{l}\text { Total bacterial } \\
\text { diversity and } \\
\text { relative abundance }\end{array}$ & $\begin{array}{l}\text { The PCR primer pair }(341 \mathrm{~F} / 806 \mathrm{R}) \\
\text { targeting the } \mathrm{V} 3-\mathrm{V} 4 \text { variable } \\
\text { regions of the } 16 \mathrm{~S} \text { rRNA }\end{array}$ \\
\hline [51] & 16S rRNA PCR & $\begin{array}{l}\text { Unstimulated } \\
\text { saliva samples }\end{array}$ & $\begin{array}{l}120 \text { (64 healthy controls; } \\
56 \text { from cancer patients) }\end{array}$ & $\begin{array}{l}\text { Total bacterial } \\
\text { diversity and } \\
\text { relative abundance }\end{array}$ & $\begin{array}{l}\text { The PCR primer pair }(341 \mathrm{~F} / 806 \mathrm{R}) \\
\text { targeting the } \mathrm{V} 3-\mathrm{V} 4 \text { variable } \\
\text { regions of the } 16 \mathrm{~S} \text { rRNA }\end{array}$ \\
\hline [36] & 16S rRNA PCR & $\begin{array}{l}\text { Unstimulated } \\
\text { saliva samples }\end{array}$ & $\begin{array}{c}24 \text { (8 healthy controls; } \\
16 \text { OSCC) }\end{array}$ & $\begin{array}{l}\text { Total bacterial } \\
\text { diversity and } \\
\text { relative abundance }\end{array}$ & $\begin{array}{l}\text { The PCR primer pair }(515 \mathrm{~F} / 806 \mathrm{R}) \\
\text { targeting the V4 region of the } 16 \mathrm{~S} \\
\text { rRNA was used }\end{array}$ \\
\hline [37] & 16S rRNA PCR, IHC & Tissue biopsy samples & 212 (HNSCC) & $\begin{array}{l}\text { F. nucleatum; } \\
\text { gram-negative } \\
\text { bacteria }\end{array}$ & $\begin{array}{l}\text { A unique PCR primer for F. } \\
\text { nucleatum; LPS monoclonal } \\
\text { Mouse antibody (clone C8) }\end{array}$ \\
\hline [38] & 16S rRNA PCR & $\begin{array}{l}\text { Unstimulated } \\
\text { saliva samples }\end{array}$ & $\begin{array}{c}49 \text { (24 healthy controls; } \\
25 \text { OSCC) }\end{array}$ & $\begin{array}{l}\text { Total bacterial } \\
\text { diversity and } \\
\text { relative abundance }\end{array}$ & $\begin{array}{l}\text { The PCR primer pair (16SF/16SR) } \\
\text { targeting the V3-V4 variable } \\
\text { regions of the } 16 S \text { rRNA }\end{array}$ \\
\hline [39] & 16S rRNA PCR & Tissue biopsy samples & $\begin{array}{c}100 \text { (50 paracancerous } \\
\text { control tissues; } \\
50 \text { tumor tissues) }\end{array}$ & $\begin{array}{l}\text { Total bacterial } \\
\text { diversity and } \\
\text { relative abundance }\end{array}$ & $\begin{array}{l}\text { A PCR primer pair targeting the } \\
\text { V3-V4 variable regions of the } 16 \mathrm{~S} \\
\text { rRNA was used }\end{array}$ \\
\hline$[40]$ & 16S rRNA PCR & $\begin{array}{l}\text { Oral swabs from tumor } \\
\text { and normal tissues }\end{array}$ & $\begin{array}{c}232 \text { (116 contralateral } \\
\text { normal tissues, } \\
116 \text { tumor tissues) }\end{array}$ & $\begin{array}{l}\text { Total bacterial } \\
\text { diversity and } \\
\text { relative abundance }\end{array}$ & $\begin{array}{l}\text { The PCR primer pair }(515 \mathrm{~F} / 806 \mathrm{R}) \\
\text { targeting the V4 region of the } 16 \mathrm{~S} \\
\text { rRNA was used }\end{array}$ \\
\hline
\end{tabular}

F. naviforme, Fusobacterium naviforme; F. nucleatum, Fusobacterium nucleatum; HNSCC, head and neck squamous cell carcinoma; IHC, immunohistochemistry; LPS, Lipopolysaccharide; NPC, nasopharyngeal cancer; OPMDs, oral potentially malignant disorders; OSCC, oral squamous cell carcinoma; P. gingivalis, Porphyromonas gingivalis P. melanogenica; Prevotella melanogenica; PCR, polymerase chain reaction; rRNA, ribosomal RNA; S. anginosus, Streptococcus anginosus; S. gordonii, Streptococcus gordonii. 


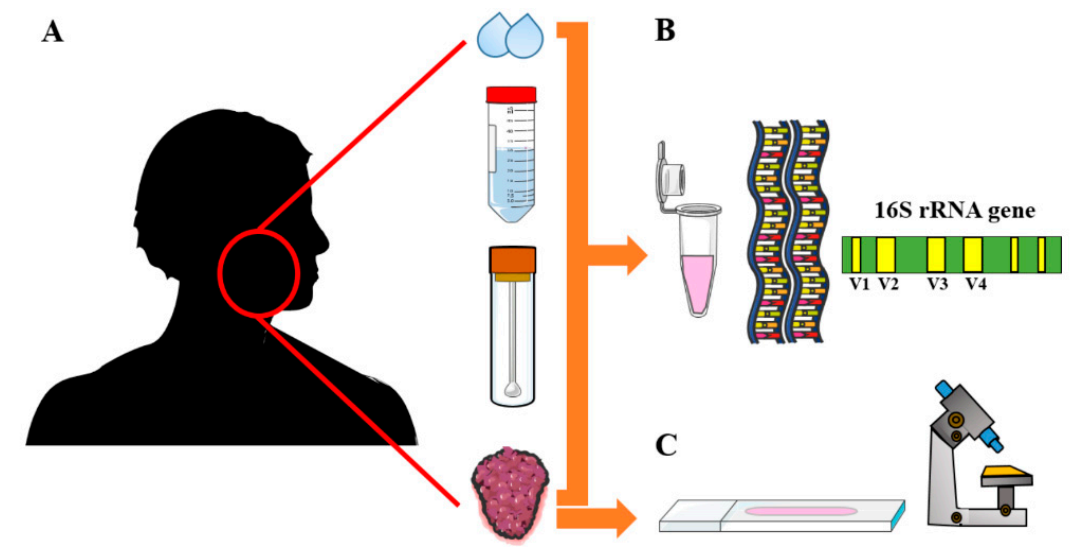

Figure 2. The different methods used for collecting and characterizing oral microbiota from patients with head and neck squamous cell carcinoma. (A) Oral microbiota samples are obtained by means of saliva expectoration; mouth wash samples; oral swab samples; or tissue biopsy. (B) Oral microbiota were characterized by DNA-DNA hybridization; primers targeting the $16 \mathrm{~S}$ ribosomal RNA gene. (C) Immunohistochemistry of tumor sections was also used to identify oral microbiota.

\subsection{Reporting Quality and the Risk of Bias}

To assess the reporting quality of the included studies, we applied six REMARKadapted items. Of note, only one study fulfilled all of the applied criteria while the rest had at least one missing item. The MAStARI tool revealed that the risk of bias was low in 15 studies (44\%), moderate in 14 studies (41\%), and high in 5 studies (15\%). The results for each study using the REMARK and MAStARI assessment tools are detailed in the Table S3.

\subsection{Oral Microbiota and OPMDs}

The relationship between oral microbiota and OPMDs was assessed in 6 studies. Schmidt et al. found that pyhla Firmicutes and Actinobacteria were significantly decreased in the "pre-cancer" lesions including mild, moderate and severe oral epithelial dysplasia compared to the healthy controls [41]. In agreement, Lee et al. found that the epithelial precursor lesions (e.g., dysplasia) had less abundant genera such as Bacillus, Enterococcus, Parvimonas, Peptostreptococcus and Slackia [22]. In contrast to these findings, Gopinath et al. showed that Megaspheara, unclassified Enterobacteriae, Prevotella, and Salmonella were more expressed in oral leukoplakia compared to healthy controls. Additionally, the authors reported a clear overlap between the whole mouth fluid bacteriome of leukoplakia and oral cancer [33]. Similarly, Hashimoto et al. found a significantly higher level of the genus Streptococcus in oral leukoplakia than in OSCC [30]. This was further supported by Ganly et al., who showed that Genera Fusobacterium and Veillonella were significantly increased in OPMDs [29]. Mok et al. demonstrated that phyla Firmicutes and Bacteroidetes had more OPMD related bacteria groups compared to healthy and cancer groups [42].

\subsection{Oral Microbiota and OSCC}

As the findings from OSCC studies are extensive, we will only present the statistically significant results. Recently, phyla of Actinobacteria and Cyanobacteria were decreased in OSCC ( $p=0.021$ and $p=0.013$, respectively) compared to paracancerous tissue from the same patients [35]. Yang et al. showed that only Fusobacterium was increased while Streptococcus, Haemophilus, Porphyromonas and Actinomyces were all decreased $(p<0.0001)$ in OSCC compared to healthy controls [26]. In another recent study, genera Peptostreptococcus, Fusobacterium, Alloprevotella, and Capnocytophaga were all increased in contrast to decreased Rothia and Haemophilus $(p<0.05)$ in OSCC compared to non-cancer controls [31]. In agreement, OSCC patients had elevated levels of Peptostreptococcus, Fusobacterium, Alloprevotella and Capnocytophaga, while Rothia Streptococcus and Veillonella were all decreased $(p<0.05)$ [32]. Supporting these findings, genera Prevotella, Fusobacterium and Alloprevotella were increased 
in OCSCC ( $p=0.019, p=0.016$ and $p=0.011$, respectively) compared with normal control patients. Interestingly, these genera showed a trend to increase from healthy controls to OPMDs with their highest level seen in OSCC [29]. In contrast, Streptococcus was found decreased in OSCC [29]. Torralba et al. found a higher abundance of Prevotella in saliva from OSCC patients [34]. Hashimoto et al. demonstrated that phylum Bacteroidetes and genus Solobacterium had higher relative abundance in the OSCC group $(p<0.05)$ than patients with oral leukoplakia [30].

Granato et al. conducted a comparison of oral microbiota in OSCC patients before (L0) and after (L1) surgical excision [36]. Compared with the healthy controls, genera Abiotrophia, Acinetobacter, Alloscordovia, Dialister, Gemella, Granulicatella, Peptostreptococcus, Selenomonas, Staphylococcus, and Stenotrophomonas were considerably higher in both L0 and L1 patients. On the other hand, genera Veillonella, Rothia, Moryella, Kingella, and Centipeda were reduced in both groups. However, L1 patients had higher Alloscordovia and reduced Veillonella levels compared to L0 patients [36]. Very recently, Su et al. identified significant alterations in the bacterial diversity and relative abundance of specific oral microbiota with the most profound finding was the enrichment of Fusobacterium and the loss of Streptococcus in the OSCC [40]. Furthermore, authors suggested that genera Streptococcus, Fusobacterium, Peptostreptococcus, Campylobacter and species Streptococcus pneumoniae and F. Nucleatum (strain CTI-2) could be potential biomarkers for cancer patients [40]. The studied oral microbiota with their relative abundance in OSCC are depicted in Figure 3.
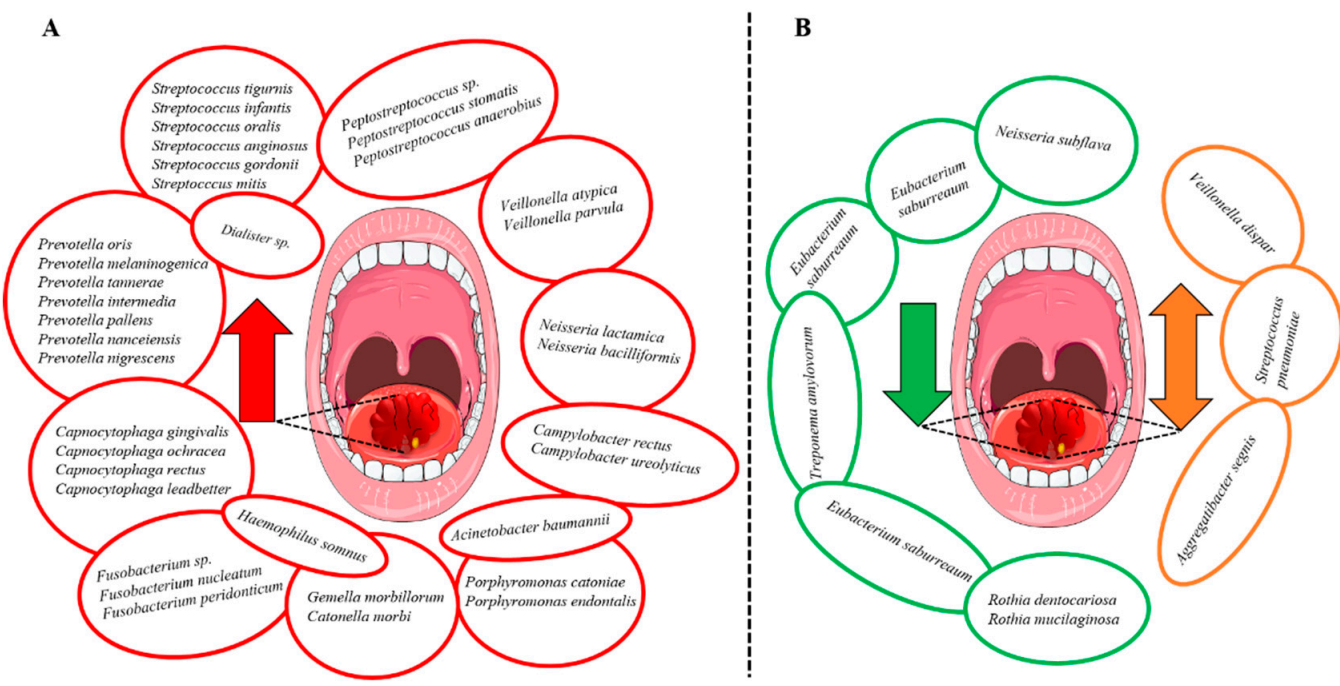

Figure 3. The relative abundance of the studied oral microbiota in oral squamous cell carcinoma (OSCC). (A) The bacterial species shown to have a higher abundance in OSCC (red circles; red arrow). (B) The bacterial species shown to have a lower abundance in OSCC (green circles; green arrow). In addition, a few species were shown to be increased in some studies and decreased in others (orange circles; orange double-headed arrow).

\subsection{Oral Microbiota in Other Types of HNSCC}

Debelius et al. explored the relationship between NPC and the oral microbiota using 16S rRNA sequencing of 499 NPC patients. They found that the overall microbial diversity was lower in NPC patients compared to healthy controls $(p<0.001)$. They also identified a pair of Granulicatella adiacens amplicon sequence variants were strongly associated with NPC status [46]. Hayes et al. studied mouthwash samples from 129 HNSCC patients including cancers of pharynx, larynx and the oral cavity. Greater levels of genera Corynebacterium, Kingella, Neisseria, Abiotrophia, Capnocytophaga and species Kingella denitrificans and Streptococcus sanguinis were associated with a reduced risk for larynx cancer [48]. Likewise, species Actinomyces oris and Veillonella denticariosi were associated with a reduced risk of 
pharynx cancer. However, there were no bacterial genera associated with oral cavity or pharynx cancer [48].

As tumor site was strongly associated with the T-stage, Wang et al. stratified their 121 samples of HNSCC based on location: oral cavity/oropharynx versus hypopharynx/larynx, phyla Actinobacteria was increased in low T-stage patients $(p=0.031)$, while genera Actinomyces and Parvimonas were not significantly changed [47]. In the group of oral cavity/oropharynx, Actinobacteria and Actinomyces approached significance in low T-stage patients relative to higher stages ( $p=0.100, p=0.192$, respectively), while Parvimonas remained decreased among low T-stage patients $(p=0.006)$ [47]. In one study on GSCC, Katz et al. performed immunohistochemical staining to assess the presence of $p$. gingivalis and Streptococcus gordonii in tissue sections from GSCC. They showed a higher level of $P$. gingivalis (more than $33 \%, p<0.05$ ) in the carcinoma samples compared to normal gingiva. The staining intensity was also enhanced for $P$. gingivalis compared to specimens stained for the S. gordonii [44].

\subsection{Oral Dysbiosis and Tumor Progression in HNSCC}

A possible involvement of oral microbiota in dictating the progression of HNSCC was reported in seven studies $[26,27,31,36,37,47,49]$. For instance, Fusobacteria was increased during tumor development from stages 1 to 4 in patients with OSCC [26]. In contrast, Actinobacteria and Bacteroidetes were significantly decreased during cancer progression [26,47]. However, higher levels of Bacteroidetes have recently been linked to one of the mutational signature clusters associated with both late stages and larger sizes of OSCC [27]. Higher levels of Fusobacterium [49], Rothia [31], and Actinomyces [47] were associated with a lower T-stage, whereas Parvimonas was decreased in this stage [47] and amount of Peptostreptococcus positively related to a higher stage [49]. Veillonella was inversely correlated with clinical tumor size, lesion, and clinical stage of OSCC patients [36]. Recently, Neuzillet et al. reported that positivity of $F$. nucleatum was associated with a lower T-stage of OSCC. Furthermore, toll-like receptor 4 and the recruitment of M2-macrophages were both significantly decreased in tumors with high $F$. nucleatum load suggesting a better clinical outcome [37]. In another recent study on OSCC, Su et al. showed that oral dysbiosis can attenuate the production of anticancer metabolites such as the siderophore group nonribosomal peptides, monoterpenoid biosynthesis and others [40]. Katz et al. reported that tissue abundance of $P$. gingivalis was associated with the poorly differentiated GSCC, although it was not statistically significant [44].

The Operational Taxonomic Units (OTUs), using mothur's Bayesian classifier, were suggested as predictors of tumor metastasis. Schmidt et al. found that 11 OTUs from Actinomyces, Rothia and Streptococcus were associated with OSCC while only 1 OTU from Fusobacterium was linked to normal samples. This set of OTUs was analyzed and it separated most cancers from other samples with the greatest separation of node metastasis cases [41]. A higher level of Actinobacteria was associated with TP53 mutations, while Firmicutes was associated with recurrent mutations in key driver genes (FAT1, FZR1, and AXIN1) related to the Wnt pathway [27]. However, Ganly et al. found no association between bacterial taxa and tumor stage or metastasis [29].

\subsection{The Prognostic Value of Oral Microbiota in HNSCC}

A total of five studies reported prognostic data associated with oral microbiota (Table 3). Recently, Granato et al. demonstrated that a higher relative abundance of Stenophotromonas, Staphylococcus, Centipeda, Selenomonas, Alloscordovia, and Acinetobacter in saliva was associated with poor overall survival of OSCC patients [36]. In contrary, Veillonella relative abundance inversely correlates with clinical tumor size and clinical stage, suggesting a better prognosis for OSCC patients [36]. Neuzillet et al. concluded that OSCC patients with F. nucleatum-positive samples had longer relapse-free survival (median: 7.06 vs. 2.11 months, $p=0.0091$ ) and metastasis-free survival (9.71 vs. 3.54 months, $p=0.0016)$ compared to F. nucleatum-negative tumors [37]. Consistently, a higher relative 
abundance of F. nucleatum in tumor tissue was correlated with a better 3-year diseasespecific survival and disease-free survival. This elevated status of F. nucleatum was also associated with non-smokers, lower tumor stage, lower rate of recurrence. Further, depletions of Neisseria, Haemophilus, and Rothia in HNSCC cases were associated with worse cancer-specific survival [49]. Robayo et al. analyzed the survival data of HPV-positive OSCC patients with those co-infected with HPV and Streptococcus anginosus. A tendency towards a poorer survival outcome was recognized for patients co-infected with both microorganisms, although it was not statistically significant [43]. As a novel finding, Capnocytophaga, a genus of gram-negative bacteria, was significantly increased in patients with recurrent OSCC after tumor resection, with a median abundance of 5.62-fold higher than in normal control patients [29].

Table 3. The prognostic value of oral microbiota in head and neck squamous cell carcinoma.

\begin{tabular}{|c|c|c|c|c|c|c|}
\hline Study & Cancer Type & Statistics & Analysis Target & Analysis Results & Prognostic Effect & Result Interpretation \\
\hline [29] & OSCC & $\begin{array}{l}\text { Kruskal Wallis and } \\
\text { Mann-Whitney tests }\end{array}$ & RA and recurrence & $\begin{array}{l}\text { Capnocytophaga was higher } \\
\text { in recurrent tumors } \\
\text { (median }=1.54 \text { vs. } 0.27 \% \text { ); } \\
\quad p=0.0083\end{array}$ & Unfavorable & $\begin{array}{l}\text { Capnocytophaga is associated with } \\
\text { OSCC recurrence. In contrast, no } \\
\text { taxa were associated with the } \\
\text { tumor stage, lymph node status, } \\
\text { or distant metastasis }\end{array}$ \\
\hline [43] & OSCC & $\begin{array}{l}\text { Kaplan-Meier and } \\
\text { Log-Rank tests }\end{array}$ & $\begin{array}{l}\mathrm{HPV}^{+\mathrm{ve}} \text { patients } \\
\text { vs. } \mathrm{HPV}^{+\mathrm{ve}} / \\
\text { S. anginosus } \\
\text { patients }\end{array}$ & $\begin{array}{l}\text { No statistically significant } \\
\text { differences were observed; } \\
\qquad p=0.559\end{array}$ & $\begin{array}{l}\text { Potentially } \\
\text { unfavorable }\end{array}$ & $\begin{array}{c}\mathrm{HPV}^{+\mathrm{ve}} / \text { S. anginosus } \\
\text { tend patients } \\
\text { outcomes although it was } \\
\text { not significant }\end{array}$ \\
\hline [49] & HNSCC & $\begin{array}{l}\text { Uni-/Multi-variate } \\
\text { analyses }\end{array}$ & $\begin{array}{l}\text { RA and clinical } \\
\text { prognostic factors }\end{array}$ & $\begin{array}{c}\text { F. nucleatum enrichment } \\
\text { had better } 3 \text {-year DSS } \\
\text { (86.7\% vs. } 47.6 \%, \\
p \leq 0.001) ; \text { DFS }(85.0 \% \text { vs. } \\
41.8 \%, p \leq 0.001) \\
\text { lower T-stage }\end{array}$ & Favorable & $\begin{array}{c}\text { Fusobacterium is an independent } \\
\text { predictor of DSS and may } \\
\text { facilitate the use of oral bacteria } \\
\text { as biomarkers in patients } \\
\text { with HNSCC }\end{array}$ \\
\hline [36] & OSCC & $\begin{array}{l}\text { Kaplan-Meier and } \\
\text { Log-Rank tests; } \\
\text { Pearson correlation } \\
\text { coefficient and } \\
\text { cross-tabulation with } \\
\text { the chi-square test }\end{array}$ & $\begin{array}{l}\text { RA and clinical } \\
\text { prognostic factors }\end{array}$ & $\begin{array}{l}\text { Enrichment of six genera } \\
\text { (Stenotrophomonas, } \\
\text { Staphylococcus, Selenomonas, } \\
\text { Centipeda, Alloscardovia, } \\
\text { and Acinetobacter) had } \\
\text { shorter OS }(p<0.05) ; \\
\text { Veillonella and Centipeda } \\
\text { were correlated with tumor } \\
\text { size and clinical stage }\end{array}$ & Unfavorable & $\begin{array}{l}\text { Oral microbiota and their protein } \\
\text { abundance have potential } \\
\text { diagnosis and prognosis value for } \\
\text { oral cancer patients }\end{array}$ \\
\hline [37] & OSCC & $\begin{array}{l}\text { Kaplan-Meier and } \\
\text { Log-Rank tests; } \\
\text { Uni-/Multi-variate } \\
\text { analyses; Chi-square } \\
\text { correlation test }\end{array}$ & $\begin{array}{l}\text { Intratumoral } F \text {. } \\
\text { nucleatum and clinical } \\
\text { prognostic factors }\end{array}$ & $\begin{array}{l}\text { In the merged cohort, } \\
\text { F. nucleatum }{ }^{+\mathrm{ve}} \text { tumors had } \\
\text { better OS than negative } \\
\text { tumors (HR: } 0.51, p=0.009 \text {; } \\
\text { 5-year OS } 60.5 \% \text { vs. } 37.7 \% \text {; } \\
\text { 10-year OS } 47.9 \% \\
\text { vs. } 18.8 \% \text { ) }\end{array}$ & Favorable & $\begin{array}{c}\text { F. nucleatum identified a subgroup } \\
\text { of OSCC; it was frequent in older, } \\
\text { non-drinking patients; associated } \\
\text { with less lymph node invasion } \\
\text { and distant relapse. F. nucleatum } \\
\text { expression showed favorable OS } \\
\text { (independent predictor), RFS and } \\
\text { MFS outcomes in the } \\
\text { merged cohort }\end{array}$ \\
\hline
\end{tabular}

RA, relative abundance; F. nucleatum, Fusobacterium nucleatum; HNSCC, head and neck squamous cell carcinoma; OSCC, oral squamous cell carcinoma; S. anginosus, Streptococcus anginosus; S. gordonii, Streptococcus gordonii; DSS, disease-specific survival; DFS, disease-free survival; OS, overall survival; MFS, metastasis-free survival; RFS, relapse-free survival.

\section{Discussion}

In the present systematic review, we summarized and analyzed a total of 34 studies involving 4432 participants, of which 2294 were HNSCC patients. The included studies evaluated the relationship between oral microbiota and HNSCC. Bacterial genera that were increased in abundance in HNSCC patients included Fusobacterium [26,29,31,32,40], Peptostreptococcus [22,31,32,40], Alloprevotella [29,31,32], Capnocytophaga [31,32,40] and Prevotella [29,34,40]. Additionally, the species Prevotella melaninogenica [18,24], F. nucleatum $[24,32,37,40]$ and Prevotella intermedia [24,32] were increased in HNSCC (Figure 3A). In contrast, certain bacterial genera including Streptococcus [26,29,32,34,40], Haemophilus [26,31], Rothia [31,32,34,36] and Veillonella $[32,34,36]$ were decreased (Figure 3B). However, the findings were not always consistent since Veillonella dispar [24,38], Aggregatibacter segnis [32,38] and S. pneumoniae [34,40] were shown to be both increased and decreased in patients with HNSCC (Figure 3B). Survival outcomes were negatively associated with the decreased abundance of Haemophilus and Rothia. In contrast, genera Fusobacterium and species F. nucleatum were associated with improved survival and lower recurrence rates. 
To our knowledge, this is the first systematic review to compile and analyze an extensive amount of clinical data regarding the association between oral microbiota and different aspects of HNSCC. Although it was challenging to perform this study, yet it exhibits several strengths. Given the newness of this field and its limited experimental approaches, our comprehensive search, via multiple databases, yielded studies with a relatively large number of patients. Secondly, the study design was based on the PRISMA guidelines with a PROSPERO-registered protocol. Finally, the included studies were qualitatively appraised using both quality control and bias analysis tools. However, we acknowledge certain limitations. More than half of the eligible studies showed a tendency towards a reporting bias (i.e., moderate and high). This could be in part explained by the failure to perform a sufficient analysis of the patients' data. Additionally, prognostic studies were limited and the REMARK criteria were not always applied. Unfortunately, variations among the studies did not permit us to conduct a meta-analysis. Finally, our analysis was restricted only to data reported in English language; thus, this study may not reveal all the available knowledge in the field.

The analyzed microbiota was isolated from saliva, oral swabs, and/or tissue samples (Figure 2). Although saliva was the most commonly used sample, there was a variation in the collection techniques including oral washes, stimulated and unstimulated saliva. These variations could subsequently affect the bacterial composition and hence the results' compatibility [6,7]. Furthermore, results inconsistency in onco-microbiome studies could arise from focusing on the compositional analysis alone, which does not account for functional redundancy in oral microbiota [25]. Tissue samples were utilized only in a few studies with a smaller cohort size as compared to studies based on salivary analysis. Noteworthy, the controls were not always healthy or cancer-free individuals in these studies. In a recent OSCC study, for instance, the negative controls comprised patients with thyroid nodules (benign and malignant). However, these patients were considered representative of normal population as they showed no evidence of oral cavity pathology following close clinical examinations [29].

Oral microbiota were shown to be associated with cancers other than HNSCC including lung, colorectal and pancreatic cancers $[9,11]$. Importantly, carcinogenesis has recently been linked to periodontitis - a chronic inflammation largely mediated by oral dysbiosis [10]. In a recent meta-analysis, periodontitis and periodontal bacteria were associated with an increased incidence of cancer and poor survival rates. Interestingly, authors found that a higher cancer risk was associated with $P$. gingivalis and $P$. intermedia but not with F. nucleatum, Tannerella forsythia, Treponema denticola or Aggregatibacter actinomycetemcomitans [10]. Fusobacterium, specifically F. nucleatum, has a strong association to the tumorigenesis of colorectal cancer [52-54]. In agreement with this evidence, our review demonstrated that genus Fusobacterium $[26,29,31,32,40]$ and F. nucleatum $[24,32,37,40]$ are connected to HNSCC. However, it was also proposed that abundance of Fusobacterium could have a favorable effect on HNSCC progression and survival [37,49]. Another wellstudied species is $P$. gingivalis, an anaerobic bacteria that has been connected among others to pancreatic cancer [55,56] and OSCC [57-59]. Noteworthy, only one study showed a statistically significant evidence of the association between $P$. gingivalis and HNSCC using immunostaining on tissue samples [44]. This finding raises the question whether stimulated/unstimulated saliva, swabs or tissue samples would represent the most reliable method for analyzing oral microbiota in cancer patients. Data are, however, conflicting in this regard. While unstimulated saliva was considered inferior to stimulated saliva [60,61], another study showed that there are no major differences in their reliability [62].

The utility of oral microbiota as biomarkers in HNSCC has also been elucidated. Lee et al. proposed that differences in the abundance of genera Bacillus, Parvimonas, Peptostreptococcus and Slackia could be used as a marker for the prediction, detection, and prognosis of patients with OSCC [22]. Su et al. had results supporting that the profusion of F. nucleatum (strain CTI-2) and a decreased abundance of $S$. pneumoniae could distinguish cancers from healthy controls [40]. Indeed, a prediction tool for metastasis would be crucial 
since locoregional metastasis can drastically worsen the prognosis of HNSCC patients [63]. In this context, it was suggested that certain OTUs can separate node-positive cases from the negative ones in patients with OSCC [41]. Additionally, studies indicated that oral microbiota can substantially change through the course from potentially malignant lesions to cancer $[22,29,33]$. This finding could have a clinical utility in future. Currently, the follow-up of OPMDs is based on the clinical appearance of the lesion and, if needed, a surgical biopsy. Thus, obtaining saliva to follow up any changes in the microbiota, together with the clinical inspection, could provide clinicians with a simple, non-invasive, approach to early diagnosing malignant changes of OSCC.

The potential role of oral microbiota in modifying the immune response in tumor microenvironment (TME) has been studied. For instance, it has been shown that infection with F. nucleatum enhanced M2 polarization of macrophages through TLR-4 activation, which increased tumor growth in colorectal cancer [64]. In this regard, higher levels of M2 macrophages showed poorer prognosis and clinical outcomes in HNSCC patients $[65,66]$. Controversially, one study reported that high levels of F. nucleatum was associated with decreased recruitment of M2-macrophages and low TLR4 signaling and lower T-stage [37]. Patients with HNSCC are often given antibiotics during the course of treatment. In the included studies, the oral microbiota samples were collected either prior to the treatment or without reporting which antibiotics were given. Thus, a detailed follow-up regarding the change in oral microbiota due to the administration of antibiotics and their possible effect on cancer progression is needed in the future studies.

\section{Conclusions}

This systematic review asserts the association of oral microbiota to the tumorigenesis of HNSCC. Microbial dysbiosis is evident in HNSCC patients and several bacterial genera and species seem to affect HNSCC progression, metastasis, recurrence, and/or survival. However, it remains uncertain exactly which genera, species or bacteria combinations are truly significant. Therefore, we encourage further research in this newly emerging area, which could lead to the development of effective diagnostic and prognostic targets and even therapeutic measures for patients with HNSCC.

Supplementary Materials: The following are available online at https: / www.mdpi.com/article / 10.3390/cancers14010046/s1, Table S1: The inclusion and exclusion criteria applied in this study, Table S2: Evaluation criteria used to assess the reporting quality of the included studies, Table S3: The risk of bias and reporting quality of the included studies.

Author Contributions: Conceptualization, A.S. and T.S.; methodology, M.M. and S.H.; formal analysis, M.M. and S.H. and A.S.; resources, A.S. and T.S.; writing-original draft preparation, M.M.; writing - review and editing, A.S.; project administration, A.S. and T.S.; funding acquisition, A.S. and T.S. Open access funding provided by University of Helsinki. All authors have read and agreed to the published version of the manuscript.

Funding: This research was funded by: The MD-PhD Program, Faculty of Medicine, University of Helsinki; Jane and Aatos Erkko Foundation; The Minerva Foundation Institute for Medical Research; Cancer Society of Finland; Sigrid Jusélius Foundation; Helsinki University Central Hospital research funds; Oulu University Hospital MRC grant.

Conflicts of Interest: The authors declare no conflict of interest.

\section{References}

1. Johnson, D.E.; Burtness, B.; Leemans, C.R.; Lui, V.W.Y.; Bauman, J.E.; Grandis, J.R. Head and neck squamous cell carcinoma. Nat. Rev. Dis. Primers 2020, 6, 92. [CrossRef]

2. Warnakulasuriya, S. Global epidemiology of oral and oropharyngeal cancer. Oral Oncol. 2009, 45, 309-316. [CrossRef]

3. Sung, H.; Ferlay, J.; Siegel, R.L.; Laversanne, M.; Soerjomataram, I.; Jemal, A.; Bray, F. Global Cancer Statistics 2020: GLOBOCAN Estimates of Incidence and Mortality Worldwide for 36 Cancers in 185 Countries. CA Cancer J. Clin. 2021, 71, 209-249. [CrossRef]

4. Economopoulou, P.; De Bree, R.; Kotsantis, I.; Psyrri, A. Diagnostic Tumor Markers in Head and Neck Squamous Cell Carcinoma (HNSCC) in the Clinical Setting. Front. Oncol. 2019, 9, 827. [CrossRef] [PubMed] 
5. Vigneswaran, N.; Williams, M.D. Epidemiologic Trends in Head and Neck Cancer and Aids in Diagnosis. Oral Maxillofac. Surg. Clin. N. Am. 2014, 26, 123-141. [CrossRef] [PubMed]

6. Mosaddad, S.A.; Tahmasebi, E.; Yazdanian, A.; Rezvani, M.B.; Seifalian, A.; Yazdanian, M.; Tebyanian, H. Oral microbial biofilms: An update. Eur. J. Clin. Microbiol. Infect. Dis. 2019, 38, 2005-2019. [CrossRef]

7. Arweiler, N.B.; Netuschil, L. The Oral Microbiota. Adv. Exp. Med. Biol. 2016, 902, 45-60. [CrossRef]

8. Kilian, M.; Chapple, I.L.C.; Hannig, M.; Marsh, P.D.; Meuric, V.; Pedersen, A.M.L.; Tonetti, M.S.; Wade, W.G.; Zaura, E. The oral microbiome-An update for oral healthcare professionals. Br. Dent. J. 2016, 221, 657-666. [CrossRef]

9. Irfan, M.; Delgado, R.Z.R.; Frias-Lopez, J. The Oral Microbiome and Cancer. Front. Immunol. 2020, 11, 591088. [CrossRef] [PubMed]

10. Xiao, L.; Zhang, Q.; Peng, Y.; Wang, D.; Liu, Y. The effect of periodontal bacteria infection on incidence and prognosis of cancer: A systematic review and meta-analysis. Medicine 2020, 99, e19698. [CrossRef]

11. Teles, F.; Alawi, F.; Castilho, R.; Wang, Y. Association or Causation? Exploring the Oral Microbiome and Cancer Links. J. Dent. Res. 2020, 99, 1411-1424. [CrossRef]

12. Schwabe, R.F.; Jobin, C. The microbiome and cancer. Nat. Rev. Cancer 2013, 13, 800-812. [CrossRef] [PubMed]

13. Li, M.; Zhou, H.; Yang, C.; Wu, Y.; Zhou, X.; Liu, H.; Wang, Y. Bacterial outer membrane vesicles as a platform for biomedical applications: An update. J. Control. Release 2020, 323, 253-268. [CrossRef] [PubMed]

14. Guo, Q.; Li, X.; Zhou, W.; Chu, Y.; Chen, Q.; Zhang, Y.; Li, C.; Chen, H.; Liu, P.; Zhao, Z.; et al. Sequentially Triggered Bacterial Outer Membrane Vesicles for Macrophage Metabolism Modulation and Tumor Metastasis Suppression. ACS Nano 2021, 15, 13826-13838. [CrossRef]

15. Booth, A.; Clarke, M.; Dooley, G.; Ghersi, D.; Moher, D.; Petticrew, M.; Stewart, L. The nuts and bolts of PROSPERO: An international prospective register of systematic reviews. Syst. Rev. 2012, 1, 2. [CrossRef] [PubMed]

16. McShane, L.M.; Altman, D.G.; Sauerbrei, W.; Taube, S.E.; Gion, M.; Clark, G.M. Reporting Recommendations for Tumor Marker Prognostic Studies (REMARK). J. Natl. Cancer Inst. 2005, 97, 1180-1184. [CrossRef]

17. Hujanen, R.; Almahmoudi, R.; Karinen, S.; Nwaru, B.I.; Salo, T.; Salem, A. Vasculogenic Mimicry: A Promising Prognosticator in Head and Neck Squamous Cell Carcinoma and Esophageal Cancer? A Systematic Review and Meta-Analysis. Cells 2020, 9 , 507. [CrossRef]

18. Mager, D.; Haffajee, A.; Devlin, P.; Norris, C.; Posner, M.R.; Goodson, J. The salivary microbiota as a diagnostic indicator of oral cancer: A descriptive, non-randomized study of cancer-free and oral squamous cell carcinoma subjects. J. Transl. Med. 2005, 3, 27. [CrossRef]

19. Pushalkar, S.; Mane, S.P.; Ji, X.; Li, Y.; Evans, C.; Crasta, O.R.; Morse, D.; Meagher, R.; Singh, A.; Saxena, D. Microbial diversity in saliva of oral squamous cell carcinoma. FEMS Immunol. Med. Microbiol. 2011, 61, 269-277. [CrossRef]

20. Pushalkar, S.; Ji, X.; Li, Y.; Estilo, C.; Yegnanarayana, R.; Singh, B.; Li, X.; Saxena, D. Comparison of oral microbiota in tumor and non-tumor tissues of patients with oral squamous cell carcinoma. BMC Microbiol. 2012, 12, 144. [CrossRef]

21. Börnigen, D.; Ren, B.; Pickard, R.; Li, J.; Ozer, E.; Hartmann, E.M.; Xiao, W.; Tickle, T.; Rider, J.; Gevers, D.; et al. Alterations in oral bacterial communities are associated with risk factors for oral and oropharyngeal cancer. Sci. Rep. 2017, 7, 17686. [CrossRef]

22. Lee, W.-H.; Chen, H.-M.; Yang, S.-F.; Wen-Liang, C.; Peng, C.-Y.; Tzu-Ling, Y.; Tsai, L.-L.; Wu, B.-C.; Hsin, C.-H.; Huang, C.-N.; et al. Bacterial alterations in salivary microbiota and their association in oral cancer. Sci. Rep. 2017, 7, 16540. [CrossRef]

23. Zhao, H.; Chu, M.; Huang, Z.; Yang, X.; Ran, S.; Hu, B.; Zhang, C.; Liang, J. Variations in oral microbiota associated with oral cancer. Sci. Rep. 2017, 7, 11773. [CrossRef] [PubMed]

24. Hsiao, J.-R.; Chang, C.-C.; Lee, W.-T.; Huang, C.-C.; Ou, C.-Y.; Tsai, S.-T.; Chen, K.-C.; Huang, J.-S.; Wong, T.-Y.; Lai, Y.-H.; et al. The interplay between oral microbiome, lifestyle factors and genetic polymorphisms in the risk of oral squamous cell carcinoma. Carcinogens 2018, 39, 778-787. [CrossRef] [PubMed]

25. Perera, M.; Al-Hebshi, N.; Perera, I.; Ipe, D.; Ulett, G.; Speicher, D.; Chen, T.; Johnson, N. Inflammatory Bacteriome and Oral Squamous Cell Carcinoma. J. Dent. Res. 2018, 97, 725-732. [CrossRef]

26. Yang, C.-Y.; Yeh, Y.-M.; Yu, H.-Y.; Chin, C.-Y.; Hsu, C.-W.; Liu, H.; Huang, P.-J.; Hu, S.-N.; Liao, C.-T.; Chang, K.-P.; et al. Oral Microbiota Community Dynamics Associated With Oral Squamous Cell Carcinoma Staging. Front. Microbiol. $2018,9,862$. [CrossRef] [PubMed]

27. Yang, S.-F.; Huang, H.-D.; Fan, W.-L.; Jong, Y.-J.; Chen, M.-K.; Huang, C.-N.; Kuo, Y.-L.; Hung, S.-I.; Su, S.-C. Compositional and functional variations of oral microbiota associated with the mutational changes in oral cancer. Oral Oncol. 2018, 77, 1-8. [CrossRef]

28. Yost, S.; Stashenko, P.; Choi, Y.; Kukuruzinska, M.; Genco, C.A.; Salama, A.; Weinberg, E.; Kramer, C.D.; Frias-Lopez, J. Increased virulence of the oral microbiome in oral squamous cell carcinoma revealed by metatranscriptome analyses. Int. J. Oral Sci. 2018, 10, 32. [CrossRef]

29. Ganly, I.; Yang, L.; Giese, R.A.; Hao, Y.; Nossa, C.W.; Morris, L.G.T.; Rosenthal, M.; Migliacci, J.; Kelly, D.; Tseng, W.; et al. Periodontal pathogens are a risk factor of oral cavity squamous cell carcinoma, independent of tobacco and alcohol and human papillomavirus. Int. J. Cancer 2019, 145, 775-784. [CrossRef]

30. Hashimoto, K.; Shimizu, D.; Hirabayashi, S.; Ueda, S.; Miyabe, S.; Oh-Iwa, I.; Nagao, T.; Shimozato, K.; Nomoto, S. Changes in oral microbial profiles associated with oral squamous cell carcinoma vs leukoplakia. J. Investig. Clin. Dent. 2019, 10 , e12445. [CrossRef] 
31. Takahashi, Y.; Park, J.; Hosomi, K.; Yamada, T.; Kobayashi, A.; Yamaguchi, Y.; Iketani, S.; Kunisawa, J.; Mizuguchi, K.; Maeda, N.; et al. Analysis of oral microbiota in Japanese oral cancer patients using 16S rRNA sequencing. J. Oral Biosci. 2019, 61, 120-128. [CrossRef] [PubMed]

32. Zhang, L.; Liu, Y.; Zheng, H.J.; Zhang, C.P. The Oral Microbiota May Have Influence on Oral Cancer. Front. Cell. Infect. Microbiol. 2020, 9, 476. [CrossRef]

33. Gopinath, D.; Menon, R.K.; Wie, C.C.; Banerjee, M.; Panda, S.; Mandal, D.; Behera, P.K.; Roychoudhury, S.; Kheur, S.; Botelho, M.G.; et al. Salivary bacterial shifts in oral leukoplakia resemble the dysbiotic oral cancer bacteriome. J. Oral Microbiol. 2021, 13, 1857998. [CrossRef]

34. Torralba, M.G.; Aleti, G.; Li, W.; Moncera, K.J.; Lin, Y.-H.; Yu, Y.; Masternak, M.M.; Golusinski, W.; Golusinski, P.; Lamperska, K.; et al. Oral Microbial Species and Virulence Factors Associated with Oral Squamous Cell Carcinoma. Microb. Ecol. 2020, 82, 1030-1046. [CrossRef]

35. Zhou, J.; Wang, L.; Yuan, R.; Yu, X.; Chen, Z.; Yang, F.; Sun, G.; Dong, Q. Signatures of Mucosal Microbiome in Oral Squamous Cell Carcinoma Identified Using a Random Forest Model. Cancer Manag. Res. 2020, 12, 5353-5363. [CrossRef]

36. Granato, D.C.; Neves, L.X.; Trino, L.D.; Carnielli, C.M.; Lopes, A.F.; Yokoo, S.; Pauletti, B.A.; Domingues, R.R.; Sá, J.O.; Persinoti, G.; et al. Meta-omics analysis indicates the saliva microbiome and its proteins associated with the prognosis of oral cancer patients. Biochim. Et Biophys. Acta (BBA)-Proteins Proteom. 2021, 1869, 140659. [CrossRef]

37. Neuzillet, C.; Marchais, M.; Vacher, S.; Hilmi, M.; Schnitzler, A.; Meseure, D.; Leclere, R.; Lecerf, C.; Dubot, C.; Jeannot, E.; et al. Prognostic value of intratumoral Fusobacterium nucleatum and association with immune-related gene expression in oral squamous cell carcinoma patients. Sci. Rep. 2021, 11, 7870. [CrossRef]

38. Rai, A.K.; Panda, M.; Das, A.K.; Rahman, T.; Das, R.; Das, K.; Sarma, A.; Kataki, A.C.; Chattopadhyay, I. Dysbiosis of salivary microbiome and cytokines influence oral squamous cell carcinoma through inflammation. Arch. Microbiol. 2021, 203, 137-152. [CrossRef] [PubMed]

39. Sarkar, P.; Malik, S.; Laha, S.; Das, S.; Bunk, S.; Ray, J.G.; Chatterjee, R.; Saha, A. Dysbiosis of Oral Microbiota During Oral Squamous Cell Carcinoma Development. Front. Oncol. 2021, 11, 614448. [CrossRef] [PubMed]

40. Su, S.-C.; Chang, L.-C.; Huang, H.-D.; Peng, C.-Y.; Chuang, C.-Y.; Chen, Y.-T.; Lu, M.-Y.; Chiu, Y.-W.; Chen, P.-Y.; Yang, S.-F. Oral microbial dysbiosis and its performance in predicting oral cancer. Carcinogenesis 2021, 42, 127-135. [CrossRef]

41. Schmidt, B.L.; Kuczynski, J.; Bhattacharya, A.; Huey, B.; Corby, P.M. Changes in Abundance of Oral Microbiota Associated with Oral Cancer. PLoS ONE 2014, 9, e106297. [CrossRef] [PubMed]

42. Mok, S.F.; Karuthan, C.; Cheah, Y.K.; Ngeow, W.C.; Rosnah, Z.; Yap, S.F.; Ong, H.K.A. The oral microbiome community variations associated with normal, potentially malignant disorders and malignant lesions of the oral cavity. Malays. J. Pathol. 2017, $39,1-15$.

43. Robayo, D.A.G.; Erira, H.A.T.; Jaimes, F.O.G.; Torres, A.M.; Galindo, A.I.C. Oropharyngeal Squamous Cell Carcinoma: Human Papilloma Virus Coinfection with Streptococcus anginosus. Braz. Dent. J. 2019, 30, 626-633. [CrossRef] [PubMed]

44. Katz, J.N.; Onate, M.D.; Pauley, K.M.; Bhattacharyya, I.; Cha, S. Presence of Porphyromonas gingivalis in gingival squamous cell carcinoma. Int. J. Oral Sci. 2011, 3, 209-215. [CrossRef]

45. Lim, Y.; Fukuma, N.; Totsika, M.; Kenny, L.; Morrison, M.; Punyadeera, C. The Performance of an Oral Microbiome Biomarker Panel in Predicting Oral Cavity and Oropharyngeal Cancers. Front. Cell. Infect. Microbiol. 2018, 8, 267. [CrossRef] [PubMed]

46. Debelius, J.W.; Huang, T.; Cai, Y.; Ploner, A.; Barrett, D.; Zhou, X.; Xiao, X.; Li, Y.; Liao, J.; Zheng, Y.; et al. Subspecies Niche Specialization in the Oral Microbiome Is Associated with Nasopharyngeal Carcinoma Risk. mSystems 2020, 5, e00065-20. [CrossRef]

47. Wang, H.; Funchain, P.; Bebek, G.; Altemus, J.; Zhang, H.; Niazi, F.; Peterson, C.; Lee, W.T.; Burkey, B.B.; Eng, C. Microbiomic differences in tumor and paired-normal tissue in head and neck squamous cell carcinomas. Genome Med. 2017, 9, 14. [CrossRef]

48. Hayes, R.B.; Ahn, J.; Fan, X.; Peters, B.A.; Ma, Y.; Yang, L.; Agalliu, I.; Burk, R.D.; Ganly, I.; Purdue, M.P.; et al. Association of Oral Microbiome with Risk for Incident Head and Neck Squamous Cell Cancer. JAMA Oncol. 2018, 4, 358-365. [CrossRef] [PubMed]

49. Chen, Z.; Wong, P.Y.; Ng, C.W.K.; Lan, L.; Fung, S.; Li, J.W.; Cai, L.; Lei, P.; Mou, Q.; Wong, S.H.; et al. The Intersection between Oral Microbiota, Host Gene Methylation and Patient Outcomes in Head and Neck Squamous Cell Carcinoma. Cancers 2020, $12,3425$. [CrossRef]

50. Vesty, A.; Gear, K.; Biswas, K.; Radcliff, F.; Taylor, M.W.; Douglas, R.G. Microbial and inflammatory-based salivary biomarkers of head and neck squamous cell carcinoma. Clin. Exp. Dent. Res. 2018, 4, 255-262. [CrossRef]

51. Zuo, H.-J.; Fu, M.R.; Zhao, H.-L.; Du, X.-W.; Hu, Z.-Y.; Zhao, X.-Y.; Ji, X.-Q.; Feng, X.-Q.; Zhumajiang, W.; Zhou, T.-H.; et al. Study on the Salivary Microbial Alteration of Men with Head and Neck Cancer and Its Relationship With Symptoms in Southwest China. Front. Cell. Infect. Microbiol. 2020, 10, 514943. [CrossRef]

52. Kostic, A.D.; Chun, E.; Robertson, L.; Glickman, J.N.; Gallini, C.A.; Michaud, M.; Clancy, T.E.; Chung, D.C.; Lochhead, P.; Hold, G.L.; et al. Fusobacterium nucleatum Potentiates Intestinal Tumorigenesis and Modulates the Tumor-Immune Microenvironment. Cell Host Microbe 2013, 14, 207-215. [CrossRef] [PubMed]

53. Flanagan, L.; Schmid, J.; Ebert, M.; Soucek, P.; Kunicka, T.; Liška, V.; Bruha, J.; Neary, P.; DeZeeuw, N.; Tommasino, M.; et al. Fusobacterium nucleatum associates with stages of colorectal neoplasia development, colorectal cancer and disease outcome. Eur. J. Clin. Microbiol. Infect. Dis. 2014, 33, 1381-1390. [CrossRef] [PubMed]

54. Castellarin, M.; Warren, R.L.; Freeman, J.D.; Dreolini, L.; Krzywinski, M.; Strauss, J.; Barnes, R.; Watson, P.; Allen-Vercoe, E.; Moore, R.A.; et al. Fusobacterium nucleatum infection is prevalent in human colorectal carcinoma. Genome Res. 2012, 22, 299-306. [CrossRef] 
55. Fan, X.; Alekseyenko, A.V.; Wu, J.; Peters, B.A.; Jacobs, E.J.; Gapstur, S.M.; Purdue, M.P.; Abnet, C.C.; Stolzenberg-Solomon, R.; Miller, G.; et al. Human oral microbiome and prospective risk for pancreatic cancer: A population-based nested case-control study. Gut 2018, 67, 120-127. [CrossRef] [PubMed]

56. Michaud, D.S.; Izard, J.; Wilhelm-Benartzi, C.S.; You, D.-H.; Grote, V.A.; Tjonneland, A.; Dahm, C.C.; Overvad, K.; Jenab, M.; Fedirko, V.; et al. Plasma antibodies to oral bacteria and risk of pancreatic cancer in a large European prospective cohort study. Gut 2013, 62, 1764-1770. [CrossRef] [PubMed]

57. Ha, N.H.; Woo, B.H.; Kim, D.J.; Ha, E.S.; Choi, J.I.; Kim, S.J.; Park, B.S.; Lee, J.H.; Park, H.R. Prolonged and repetitive exposure to Porphyromonas gingivalis increases aggressiveness of oral cancer cells by promoting acquisition of cancer stem cell properties. Tumor Biol. 2015, 36, 9947-9960. [CrossRef]

58. Geng, F.; Liu, J.; Guo, Y.; Li, C.; Wang, H.; Zhao, H.; Pan, Y. Persistent Exposure to Porphyromonas gingivalis Promotes Proliferative and Invasion Capabilities, and Tumorigenic Properties of Human Immortalized Oral Epithelial Cells. Front. Cell. Infect. Microbiol. 2017, 7, 57. [CrossRef]

59. Ha, N.H.; Park, D.G.; Woo, B.H.; Kim, D.J.; Choi, J.I.; Park, B.S.; Kim, Y.D.; Lee, J.H.; Park, H.R. Porphyromonas gingivalis increases the invasiveness of oral cancer cells by upregulating IL-8 and MMPs. Cytokine 2016, 86, 64-72. [CrossRef] [PubMed]

60. Belstrøm, D.; Sembler-Møller, M.L.; Grande, M.A.; Kirkby, N.; Cotton, S.L.; Paster, B.J.; Holmstrup, P. Microbial profile comparisons of saliva, pooled and site-specific subgingival samples in periodontitis patients. PLoS ONE 2017, 12, e0182992. [CrossRef]

61. Gomar-Vercher, S.; Simon-Soro, A.; Montiel-Company, J.M.; Almerich-Silla, J.M.; Mira, A. Stimulated and unstimulated saliva samples have significantly different bacterial profiles. PLoS ONE 2018, 13, e0198021. [CrossRef] [PubMed]

62. Belstrøm, D.; Holmstrup, P.; Bardow, A.; Kokaras, A.; Fiehn, N.-E.; Paster, B.J. Comparative analysis of bacterial profiles in unstimulated and stimulated saliva samples. J. Oral Microbiol. 2016, 8, 30112. [CrossRef]

63. Cheng, A.; Schmidt, B.L. Management of the N0 Neck in Oral Squamous Cell Carcinoma. Oral Maxillofac. Surg. Clin. N. Am. 2008, 20, 477-497. [CrossRef] [PubMed]

64. Chen, T.; Li, Q.; Wu, J.; Wu, Y.; Peng, W.; Li, H.; Wang, J.; Tang, X.; Peng, Y.; Fu, X. Fusobacterium nucleatum promotes M2 polarization of macrophages in the microenvironment of colorectal tumours via a TLR4-dependent mechanism. Cancer Immunol. Immunother. 2018, 67, 1635-1646. [CrossRef]

65. Kumar, A.T.; Knops, A.; Swendseid, B.; Martinez-Outschoom, U.; Harshyne, L.; Philp, N.; Rodeck, U.; Luginbuhl, A.; Cognetti, D.; Johnson, J.; et al. Prognostic Significance of Tumor-Associated Macrophage Content in Head and Neck Squamous Cell Carcinoma: A Meta-Analysis. Front. Oncol. 2019, 9, 656. [CrossRef] [PubMed]

66. Troiano, G.; Caponio, V.C.A.; Adipietro, I.; Tepedino, M.; Santoro, R.; Laino, L.; Russo, L.L.; Cirillo, N.; Muzio, L.L. Prognostic significance of CD68+ and CD163+ tumor associated macrophages in head and neck squamous cell carcinoma: A systematic review and meta-analysis. Oral Oncol. 2019, 93, 66-75. [CrossRef] 